\title{
Subregional resource allocations in the National Health Service
}

\author{
A. H. SNAITH
}

From the Avon Area Health Authority, Bristol

SUMMARY The Resource Allocation Working Party in its report Sharing Resources for Health in England proposes a formula for the identification of both regional and district financial targets (Department of Health and Social Security, 1976). In this paper it is argued that the national formula is not a valid instrument for the latter purpose. Furthermore, research into medical needs and outcomes will not be adequate to bring about real changes in resource distribution at local levels unless it is recognised that the health authorities can meet needs in different ways and that a change in resource management from institutional to service budgeting is required.

By adopting the report of the Resource Allocation Working Party (RAWP) (Department of Health and Social Security, 1976) government is seeking to abandon incremental budgeting and to achieve equity between health regions by redistributing finance as such, in accordance with planning formulae, rather than, as formerly, by its capital investment policies for new hospitals. This methodological change represents a more profound reform than the reorganisation of the structure of the service in 1974 and the reaction to the RAWP's report has made it clear that a theory of health service planning must now be developed to stabilise discussion about health care policies at the service level within the National Health Service.

The RAWP's report (Department of Health and Social Security, 1976) is itself a first contribution to such a theory. It takes as the point of departure the fact that there are wide variations in expenditures between regions and that, very broadly, morbidity is inversely related to expenditures. In the formula which seeks to correct this the basis for redistribution of finance is weighted population. In this connection the use of mortality data as a proxy for morbidity is justified by reference to self-reported acute and chronic illness, and certified spells of incapacity. It is true that there is close agreement between mortality and the measures of morbidity used if the standard statistical regions (which are not coterminous with the health regions) are classified into High, Medium, and Low as on pages 18 and 19 of the report-that is, if levels of aggregation even greater than regions are employed. However, if the regions are placed in rank order for the three classifications: mortality, acute illness, and chronic illness, agreement, although still quite good, is $\vec{\sigma}$ less close (Table 1). Thus Yorkshire and Humberside ranks fourth in terms of overall mortality but $\vec{r}$ comes out on top in terms of morbidity. Therefore Yorkshire will do relatively badly if mortality used for determining its share of resources.

Table 1 Economic regions in rank order for mortality and morbidity

\begin{tabular}{llll}
\hline Region & Mortality & $\begin{array}{l}\text { Acute } \\
\text { illness }\end{array}$ & $\begin{array}{l}\text { Chronic } \\
\text { illness }\end{array}$ \\
\hline North & $1 \cdot 5$ & $3 \cdot 5$ & 3 \\
North-east & $1 \cdot 5$ & 7 & 7 \\
Wales & 3 & 2 & 2 \\
Yorkshire and Humberside & 4 & 1 & 1 \\
West Midllands & 5 & 8 & 5 \\
East Midlands & 6 & 6 & 4 \\
Greater London & 7 & 5 & 8 \\
South-west & 8 & 11 & 9 \\
Outer metropolitan & 9 & $3 \cdot 5$ & 11 \\
East Anglia & $10 \cdot 5$ & 10 & 6 \\
Outer south-east & $10 \cdot 5$ & 9 & 10 \\
\hline
\end{tabular}

The Spearman rank correlation coefficient for mortality and acute illness is $0.55(P=0.05)$ and for mortality and chronic illness $0.67(0.05>P>0.01)$. The Kendall coefficient of concordance for mortality, and acute and chronic illness considered together, is $0.72(0.05>P>0.02)$.

At lower levels of aggregation the inadequacy of standardised mortality ratios (SMRs) as the criteria of need will become more marked. The RAWP expresses the view that condition-specific SMRs can be used at area and district levels to compensate $\mathcal{N}$ for loss of reliability due to small numbers but it is highly probable that the advantages sought by ${ }_{N}$ greater precision concerning causes of death (and $C$ therefore morbidity and needs) in each locality will be cancelled by uncertainties because of the 
smaller numbers for condition-specific SMRs compared with overall SMRs.

The substitution of planned budgeting for incremental budgeting becomes increasingly more difficult as the descent is made through the tiers from the Department of Health and Social Security to the district. It is possible at government level because the implementation of the RAWP report 'needs' formula requires merely the redistribution of finance to the regions. The regional authorities themselves cannot so easily calculate their financial distributions by means of an abstract formula constructed from general indicators of needs such as SMRs-and then just push the money out. Immediate resource problems may have to be taken into account, not excluding, even if indirectly, the revenue consequence of capital schemes. The area authorities, concerned with actual services, have no alternative but to allocate finance to districts on a continuation basis. If what they receive as a consequence of redistribution does not coincide with the costs of their units, they have to withdraw services and the upshot is that decremental, not planned, budgeting replaces incremental budgeting. At the district level the RAWP proposes that the national formula is employed to identify target allocations so that the difference between a district's share of National Health Service resources and the theoretical share it should have can be measured. Once this is done districts below target will become predators on districts above target with the creation of enormous turbulence in the health service. Hence the need for a planning theory. The question is, can continuation budgeting be replaced by planned budgeting down to unit level in the field? The Secretary of State for Social Services (1976) has himself drawn attention to various 'unquantifiable' (sic) factors affecting local needs, including areas of social deprivation, differing levels of provision of community services, and the fact that some of the biggest inequalities are due to local variations within regions and to the presence of centres of excellence.

\section{Social deprivation and community services}

Health districts in urban conurbations have a different balance of advantages and disadvantages from those comprising discrete towns or those with large rural areas. For a century English local government has fallen into three broad classes: the shire counties, the urban conurbations, and London. Three quite different patterns of administration have always existed, reflecting very real differences in the three types of community. The reorganisation of local government in 1974 was undertaken chiefly to adjust gross imbalance which had arisen between the rich, suburban, relatively trouble-free counties and the deprived urban conurbations. The health service is orientated around the latter and not the former.

Table 2 Distribution of population by county (from OPCS monitor)

\begin{tabular}{llc}
\hline Region & $\begin{array}{l}\text { Population } \\
\text { (per thousand) }\end{array}$ & $\%$ \\
\hline England & 46417 & 100 \\
London & 7028 & 15.0 \\
Metropolitan counties & 11579 & 24.9 \\
Shire counties & 27810 & 59.9 \\
\hline
\end{tabular}

The dislocation of finance from real resources means that authorities with relatively few fixed assets may seek to provide health services by other means. A shift from hospital to community care could be encouraged, the latter compensating for inadequacies in the former. This is not the position at present. Regions with relatively good hospital provision have relatively good general practitioner and community services provision and furthermore serve populations with above average social class composition (Noyce et al., 1974). The pattern of services may therefore develop differently in deprived regions compared with previously better provided regions and, within regions, in the shire counties compared with the urban conurbations. Development of community services would not necessarily take place through the vehicle of the present community organs. Hospital staff may seek a community role and a change in interest from curing to caring. Much more direct access by consultants to the community rather than through general practitioners could be of great consequence for health care in this country. Many consultants are deeply interested in problems of rehabilitation: neurologists in stroke, urologists in incontinence, physicians in the care of the young chronic sick, or the domiciliary care of patients with ischaemic heart disease (to name four examples in Bristol backed by substantial research or special health service funding). The acute hospital may be seen increasingly as a base for community operations.

\section{Area and district variations}

Variations between areas and districts are greater than between regions. Jones and Masterman (1976) stated '. . . in all cases the variants associated with the county scale are larger than those associated with the regional scale'. They employ 12 physical variables and evidently assume uniformity of provision to be in principle desirable, but if economics is the language of choices, alternative 
forms of provision is the justification for management, and alternative methods of attack the challenge of science. The primary basis for comparison must be finance, and it is in fact not possible to achieve equal expenditures by authorities and between districts in an absolute sense. The designated regional specialties are normally sited in conurbations and allocations outside any equalisation formula have to be made for them. Therefore equality must always be notional and to some extent arbitrary. However that may be, the concentration in the conurbations and cities of high technology medicine (other than regional specialties) and of the teaching and evaluative function is likely to result in the unequal distribution of resources between the metropolitan and the shire counties and greater financial variations within regions than between regions, except to the extent that alternative and compensatory forms of provision outside the conurbations can be developed.

Jones and Masterman (1976) also stated that 'cross-boundary flows of patients making use of the facilities of neighbouring areas make little difference to the overall picture of variations'. This means that authorities within conurbations may provide more high technology medicine pro rata to their own population than they provide to neighbouring populations. Equalisation according to resident population will result in metropolitan communities receiving high technology medicine at the expense of low technology medicine and the shires the reverse. This is a pattern familiar to local government and has to do with structural problems in industrial societies; the city populations get treatment, the county populations care. Therefore it may be in the public interest for either one to have a financial advantage, or a therapeutic advantage, or a care advantage over the other, depending on the value judgements that are made, so that planned disequilibria replace inherited inequalities.

An analysis of Avon health district budgets demonstrates the remoteness of population as a foundation for the financial allocations that are actually made in a largely urban county. In Table 3 the comparable figures for cost per head of population, which are the relevant ones for any theory of equity, are barely $60 \%$ of the noncomparable figures of actual expenditures.

The non-comparable cost is the total expenditure of the health district divided by the population of the district. Some services in each district are provided not only for the district population but for a part of the whole of the population of the rest of the area, or of the region. These include designated regional specialties, special hospitals
Table 3 Financial allocations to districts per head of population (1975-76)

\begin{tabular}{|c|c|c|c|c|}
\hline \multicolumn{5}{|c|}{ Cost per head of population $(£)$} \\
\hline District & $\begin{array}{l}\text { Non- } \\
\text { comparable }\end{array}$ & $\%$ & Comparable & $\%$ \\
\hline $\begin{array}{l}\mathbf{A} \\
\mathbf{B} \\
\mathbf{C} \\
\mathbf{D} \\
\text { Average }\end{array}$ & $\begin{array}{l}80 \cdot 05 \\
67.03 \\
89 \cdot 42 \\
26.91 \\
68 \cdot 59\end{array}$ & $\begin{array}{r}116 \cdot 8 \\
97 \cdot 7 \\
130 \cdot 3 \\
38 \cdot 3 \\
100\end{array}$ & $\begin{array}{l}45 \cdot 33 \\
44 \cdot 03 \\
44 \cdot 60 \\
26 \cdot 31 \\
40 \cdot 38\end{array}$ & $\begin{array}{l}112 \cdot 2 \\
109 \cdot 0 \\
110 \cdot 0 \\
65 \cdot 1 \\
100\end{array}$ \\
\hline
\end{tabular}

and services not so designated, the hospitals for the $\frac{\mathrm{C}}{0}$ mentally ill and the mentally handicapped, and the $\overline{\bar{c}}$ maternity hospitals. The mental hospitals are in $\overrightarrow{\mathbb{D}}$ no way related to the district pattern in the area and $\propto$ they accommodate large numbers of long-stayes patients whose domicile was once elsewhere in $\overrightarrow{0}$ the UK. The 10-year target norm for mental handicap hospital beds in Avon is 600. There are ${ }_{\sigma}$ now 2800 such beds. Even maternity services have $\frac{\sigma}{\sigma}$ to be excluded from the comparable cost figures? because most births in the area take place in twow districts only. When all these exclusions have been? made the cost per head of the remaining services is $\vec{\sigma}$

very close in three districts.
In district $D$, which does appear under-privileged, $\stackrel{?}{?}$ half the patients are exported to districts A, B, and C. The judgement that has to be made is whether this really constitutes a problem that should be metô by increased hospital provision to district $\mathbb{B} . \overrightarrow{\text { C }}$ However, in districts $\mathrm{A}, \mathrm{B}$, and $\mathrm{C}$ only $50 \%$ of te patients reside in the district where they are treated $\stackrel{+\infty}{-}$ for example, in district $A$ half of the patients come from $\mathbf{B}, \mathbf{C}$, and $\mathbf{D}$. So all the districts export half of their patients, but in three these are balancedo by imports. Natural flows of patients from oneo part of a city to another are surely desirable. $\stackrel{\unrhd}{\perp}$ What value, or indeed what meaning, can therefore $\Rightarrow$ be put on a theoretical financial target for a health 3 district in a conurbation?

\section{CENTRES OF EXCELLENCE}

Two important assumptions about ex-Board of Governors (ex-BG) hospitals have been made by? the RAWP. They are, firstly, that redistribution of finance is the key problem that has to be tackled ${ }_{-}$. and, secondly, that the teaching of undergraduates accounts for most of the excess costs. Alternative propositions that require examination are, firstly, that in the context of the redistribution, according to population, of National Health Services finance? as a whole, the protection of the ex-BG hospitals' N excess costs is the key question and, secondly, that if the distribution of the excess costs indicates anything it is that they are unlikely to be accountede for by teaching. The York study (Department of Health and Social Security, 1975), on which theo RAWP report relied, demonstrated that the presence 
of students was certainly an indicator of excess costs but not that it was an explanation for them.

In the RAWP formula the excess costs of teaching hospitals are used to identify a service increment for teaching (SIFT). The method used was to ascertain the median-hospital excess cost per student and allocate according to numbers of students. Hospitals above the median position therefore lose and those below the median gain. University College Hospital and The London Hospital are about the median; Westminster is at one extreme and stands to lose about $16 \%$ of its revenue, while Newcastle is at the other and stands to gain about $13 \%$. The argument in paragraph 4.11 of the report (Department of Health and Social Security, 1976) would appear to be that the median cost is in fact the real, the objective, as it was the ascertained cost of teaching undergraduates. Therefore (the report assumes) hospitals with lower costs than the median are in that position because they have lower baseline costs (what the cost of the hospital would be if it were not a teaching hospital). 'Thus if it were possible to correct for the lower level of service provision the notional "excess costs" of these hospitals would be likely to approach the median'.

Similarly those hospitals above the median are assumed to be providing more excellence because the median cost is the true cost of teaching (and likewise the allocation for baseline costs the true baseline costs). It is simply not possible to draw valid conclusions about the true teaching costs (or baseline costs) from the calculation of the mathematical median of excess ex-BG hospital costs over ex-Regional Hospital Board (ex-RHB) hospital costs. All we know is that ex-BG hospitals cost more than ex-RHB hospitals (as judged by the ' 45 Hospital Formula') and that this excess varies from about $12 \cdot 3 \%$ at Newcastle to $43 \cdot 1 \%$ at Westminster.

The report then argues (paragraph $4 \cdot 14$ ):

A. That the median excess cost contains an element of excellence.

B. That no data are available which can be used to identify this element.

C. That unit costs for support services are high in teaching hospitals.

D. That the evidence of the York study (Department of Health and Social Security, 1975 ) is that $75 \%$ of the additional costs in teaching hospitals may be attributable to the teaching commitment.

and therefore it is recommended that $75 \%$ of the median excess cost per student ... should be used as the basis for determining the protection within allocations to be afforded through the SIFT'.

In the York study (Department of Health and Social Security, 1975) a mathematical model is used to analyse the costs structure of teaching hospitals compared with a sample group of non-teaching hospitals. Activities which contributed towards the revenue costs in the two groups are examined and it is concluded that undergraduate teaching accounted for approximately $75 \%$ of the predicted cost per case differential over RHB hospitals. This means that undergraduate teaching 'explains' the 'excess costs in a statistical sense-that is, students are an indicator or predictor of excess costs and the 'explanatory' or 'predictive' power of the model is limited, with $20 \%$ to $25 \%$ of the excess costs not 'explained' by the model. It does not mean that $75 \%$ of the excess costs are caused by undergraduate teaching (D above). It does not mean that $25 \%$ of the excess costs are caused by high unit costs for support services ( $\mathrm{C}$ above). It does not mean that the cost of the element of excellence in the median excess cost is $25 \%$ of this excess (A above).

The finding of the York study (Department of Health and Social Security, 1975) is that while there is some evidence that unit costs may be high in teaching hospitals the chief reason for excess expenditure is the increased number of units consumed. Operations are longer, more $x$-rays or pathology investigations are carried out, more meals have to be prepared, and more space has to be heated. The logical steps A, B, C, D above, which lead to the recommendation, are evidently the product of a confusion. There is no basis for the figure of $25 \%$. This has been picked up from the $25 \%$ 'unexplained' by the model.

\section{Implementation of SIFT}

Table 4 sets out figures from the report (Department of Health and Social Security, 1976) for three centres to show how the SIFT, the baseline costs, and added excellence relate to one another. Since the last two are not fixed the health authorities can change either to ensure that whatever the level of the SIFT the total allocation remains the same and so provides a continuation budget. The real as distinct from the target allocation is then determined by differential growth, from $1-3 \%$, for each region depending upon the relationship between the previous year's allocation and the target.

For example, in the North-west Thames region there are three teaching hospitals: Westminster, Charing Cross, and St Mary's. From Table IV-2, page 52 of the report, the actual allocations to the three hospitals total $£ 39$ million. The base costs 
Table 4 Financial allocations and SIFT

\begin{tabular}{|c|c|c|c|}
\hline$R A W P$ & $\begin{array}{l}\text { Category A } \\
\text { (eg. University } \\
\text { College Hospital) } \\
\text { Median } \\
\text { £'000 }\end{array}$ & $\begin{array}{l}\text { Category B } \\
\text { (eg. Newcastle) } \\
\text { (Low) } \\
\text { £'000 }\end{array}$ & $\begin{array}{l}\text { Category C } \\
\text { (eg. Westminster) } \\
\text { (High) } \\
\text { f'000 }\end{array}$ \\
\hline $\begin{array}{l}\text { (a) Baseline costs } \\
\text { (b) SIFT } \\
\text { (c) Target expenditure (a) }+ \text { (b) } \\
\text { (d) Actual allocation } \\
\text { (e) Deficit in baseline (c) - (d) } \\
\text { (f) Added centre of excellence (d) - (c) }\end{array}$ & $\begin{array}{r}8490 \\
2470 \\
11410 \\
11760 \\
350\end{array}$ & $\begin{array}{l}7550 \\
2000 \\
9550 \\
8480 \\
1070\end{array}$ & $\begin{array}{r}10090 \\
1790 \\
11880 \\
14220 \\
2340\end{array}$ \\
\hline
\end{tabular}

(a) Baseline service costs: the cost of the hospital if it were not a teaching hospital, calculated from '45' Sample Hospital Formula'.

(b) SIFT: (75\% excess median-hospital costs per student $\times$ number of students).

are $£ 27.5$ million and the excess is therefore $£ 11.5$ million. The SIFT totals $£ 6$ million and therefore the residual excess is $£ 5.5$ million. The Regional Health Authority (RHA) will receive the allocation for the previous year plus $\frac{1}{4} \%$ and $£ 11.5$ million, the gross excess of the three hospitals, will be available to the RHA within this figure. But only f6. 0 million of this is protected in the SIFT. With respect to the remaining $£ 5.5$ million the RHA must decide either to continue to support these teaching hospitals as centres of excellence as well, or redeploy some or all of this excellence money.

The northern region has received $3 \%$ growth on the previous allocation. It will not receive in addition $£ 1.07$ million added to the SIFT. If within the overall total allocation the SIFT is identified as $£ 2.0$ million instead of $£ 0.93$ million the northern region will still be allocated (the equivalent of) f8.48 million which can therefore be regarded either as $£ 7.550$ million for baseline costs and $\mathfrak{£ 0 . 9 3}$ million for teaching costs (as formerly) or as $£ 6.48$ million for baseline costs and $£ 2.0$ million for the SIFT.

The point is that a notional protection is given to the SIFT. The teaching hospitals are the only service units considered by the RAWP and it is clear that there is little objective validity in the arguments employed to support their SIFT, it is the child of administrative decisions, namely:

(a) That whereas the teaching hospitals' excess funding in 1973-74 was $£ 54.75$ million (for 5640 students) in 1977-78 it should be $£ 72.38$ million (for 9340 students). (March 1975 prices).

(b) That the excess should be distributed in accordance with student numbers.

(c) That functions of teaching hospitals other than undergraduate teaching and the excess funding required to support them, should be excluded from central consideration and become the responsibility of the health authorities-which is logical but disconcerting in that a major policy affecting the future of British medicine emerges as a consequence of financial arrangements devised on administrative grounds.

Towards a theory of health services development

\section{NEEDS}

A direct analysis of medico-social requirements is $\vec{\omega}$ the most elementary approach, conceptually, to a $\vec{D}$ theory of need for the population of a health $\stackrel{\rho}{\vec{S}}$ district-and the most elaborate and most difficult $\omega_{\mathrm{N}}$ to implement. Thus a number of workers have endeavoured to classify elderly populations into $\vec{\sigma}$ dependency subgroups and place them in a hierarchy of need (Katz et al., 1963; Culyer, 1974; Williams, 1974; Isaacs and Neville, 1976). This method attempts to formalise and thus to give a quasi-scientific status to what are largely subjective judgements about the care of patients, but is likely to oversimplif decision-making about individual patients and leag to unacceptable rigidities which erode the genuine advantages for management of clinical freedom. Furthermore it is unlikely to be applicable in acute medicine. It has been argued elsewhere that when treatment rather than care is required, competition provides a more appropriate operational model than planning (Snaith, 1976).

\section{PROVISION}

The traditional resource philosophy is to make services available and exploit them in a nonsystematic way. The most elementary approach to a theory of provision is therefore an administrative one, breaking down populations into areas for which health authorities, each with the required range of resources, are responsible. The limitation of this approach is that it resolves the problem by substituting planning assumptions for concrete achievements. It assumes a network of hospitals each with the required capability appropriately distributed throughout the country and ignores the realities which Table 3 presents.

\section{SERVICE BUDGETING}

If fantasy planning for fantasy targets is not to absorb the energies of health authorities it will be necessary to estimate for each district: 
- The balance of therapeutic advantage and financial liability in having high technology hospitals in the district (if they are present).

- The balance of therapeutic disadvantage and financial asset in not having such hospitals in the district (if they are absent).

- The extent to which alternative services can compensate for differences in the balances.

- What financial differences should remain between districts as the expression of beneficial disequilibria.

To enable such appraisals to be made, studies of both needs and outcomes on the one hand and of both real and financial resources on the other will be required. For the former the classical research methods of observation, intervention, the survey, and the clinical trial are available. Such methods cannot be applied to the resource function as it is currently conceived by management. It is not possible to evaluate an institution, only a servicefor example the cancer service, the urological service, the coronary care service, the stroke service. Therefore only if provision is itemised in service terms, not institutional terms, will it become possible to develop health services theory and practice in a way which can find practical implementation at the level of patient care. Cogwheel and the introduction in 1974 of functional budgeting accounting systems are surely precursors of integrated services which cut across traditional boundaries and are directed at and funded to meet identified real targets.

\section{Conclusions}

The RAWP has introduced a rational method of distribution of health service finance at the national level, based on targets identified by means of planning formulae (Department of Health and Social Security, 1976). The crucial step in this achievement was the dislocation of finance from real resources, thus creating the (potential) liquidity which is an essential prerequisite of planned budgeting. To object that 'the under-funded regions cannot spend the money' is like resisting the advance from a barter to a money economy. At a stroke the implementation of a theory of distribution becomes a practical possibility because the manipulation of liquid resources generates relatively little resistance. Even so, differential incremental growth represents the achievement of the RAWP and this is probably the limit of the advance that could have been made at the national level. At lower levels of population aggregation real resource considerations operate too powerfully for abstract formulae to exert much influence. SMRs (or resource utilisation data) cannot provide an appropriate instrument for the redistribution of actual health services. A more sophisticated theory of need and provision at local level must be evolved.

For this national uniformity as a desirable aim in itself must be abandoned and the development of different methods of health care by different health authorities be encouraged-a more mature planning ethos and one which follows naturally from a financial policy which aims to provide liquidity.

Administrative value judgements have relatively little force in decision-making about the management of the health care of locally defined populations (and none at all of individual patients). Scientific studies should predominate in determining policies at these levels; they should not be expected to support decisions made on administrative grounds, if only because of the confusions the misuse of science inevitably generates, such as the identification of indicator functions (undergraduates) with activity functions (those of teaching hospitals).

Reprints from A. H. Snaith, Avon Area Health Authority (T), Greyfriars, Lewin's Mead, Bristol BS1 2EE.

\section{References}

Culyer, A. J., editor (1974). Economic Policies and Social Goals: Aspects of Public Choice. Martin Robertson: London.

Department of Health and Social Security (1975). First Interim Report of the Resource Allocation Working Party. Allocation to Regions in 1976-77. HMSO: London.

Department of Health and Social Security (1976). Sharing Resources for Health in England. Report of the Resource Allocation Working Party. HMSO: London.

Isaacs, B., and Neville, Y. (1976). The needs of old people. British Journal of Preventive and Social Medicine, 30, 79-85.

Jones, D. R., and Masterman, S. (1976). NHS resources: scales of variation. British Journal of Preventive and Social Medicine, 30, 244-250.

Katz, S., Ford, A. B., Moskowitz, R. W., Jackson, B. A., and Jaffe, M. W. (1963). Studies of illness in the aged. The index of ADL: a standardised measure of biological and psychosocial function. Journal of the American Medical Association, 185,914-919.

Noyce, J., Snaith, A. H., and Trickey, A. J. (1974). Regional variations in the allocation of financial resources to the community health services. Lancet, 1 , 554-557.

Secretary of State for Social Services (1976). Outlook for NHS Resources and the Distribution between Regions. Circular No. 76/309. DHSS: London.

Snaith, A. H. (1976). Operatives and cooperatives. Administration and the clinicians. Lancet, 2, 1014-1016.

Williams, A. (1974). Measuring the effectiveness of health care systems. British Journal of Preventive and Social Medicine, 28, 196-202. 